\title{
Optimalisasi Pelayanan Apotik Panjen Di Desa Wedomartani Ngemplak Sleman Yogyakarta
}

\author{
${ }^{1}$ Lutfi Chabib*, ${ }^{2}$ Akhmad Fauzy \\ ${ }^{1)}$ Program Studi Farmasi, FMIPA Universitas Islam Indonesia Yogyakarta \\ ${ }^{2)}$ Program Studi Statistika, FMIPA Universitas Islam Indonesia Yogyakarta \\ *Corresponding Email: lutfi.chabib@uii.ac.id
}

\begin{abstract}
ABSTRAK
Kegiatan Pengabdian masyarakat yang dilakukan dalam rangka optimalisasi pelayanan Apotek Panjen, telah selesai dilaksanakan. Pelayanan kefarmasian merupakan kegiatan yang terpadu dengan tujuan untuk mengidentifikasi, mencegah, dan menyelesaikan masalah obat dan masalah yang berhubungan dengan kesehatan. Tuntutan pasien dan masyarakat akan peningkatan mutu pelayanan kefarmasian, mengharuskan adanya perluasan dari paradigma lama yang berorientasi kepada produk (Drugs Oriented) menjadi paradigma baru yang berorientasi pada pasien (Patient Oriented) dengan filosofi Pelayanan Kefarmasian (Pharmaceutical Care). Apotek Panjen di Desa Wedomartani Sleman masih terkendala dalam mengimplementasikan pelayanan kefarmasian. Berdasarkan hasil observasi ke mitra permasalahan tersebut akibat dari: Keterbatasan jumlah sumber daya manusia, minimnya sarana dan prasarana, tidak adanya etiket berstandar, tidak adanya drug information handbook, dan tidak adanya kartu konseling. Jumlah kunjungan pasien yang membeli obat di Apotek Panjen rata-rata perharinya mencapai 35-70 orang. Sehingga diperlukan peningkatan pelayanan agar dapat memberikan rasa aman kepada pasien akan pengunaan obat yang akan dikonsumsi.Hasil luaran kegiatan pengabdian ini adalah terciptanya optimalisasi pelayanan Apotek Panjen melalui peningkatan kapasitas sumber daya manusia, perbaikan sarana prasarana, terdapatnya etiket berstandar, kartu konseling, dan drug information book yang dicapai dengan model pemberdayaan masyarakat partisipatif Participatory Rural Apraisal (PRA). Keberlanjutan kegiatan pengabdian ini adalah tercapainya konsistensi penerapan sistem perapotekan yang baik dan benar, baik dari segi Pendayagunaan SDM (Sumber Daya Manusia), maupun dari segi sistem informasi manajemen perapotekan yang dapat menjamin ketersediaan obat yang tepat jenis, tepat jumlah, tepat mutu dan tepat waktu, sehingga menjadikan Apotek semakin baik dari segi pelayanan kepada masyarakat dan semakin sehat.
\end{abstract}

Kata Kunci: Apotek Panjen, pasien, pelayanan

\begin{abstract}
Community service activities have been completed to optimize Panjen Pharmacy services. Pharmaceutical services are integrated activities aimed to identify, prevent, and resolve drug problems and health-related problems. The demands of patients and society for improving the quality of pharmaceutical services require the expansion of the old drugs-oriented paradigm into a new patient-oriented paradigm with the philosophy of Pharmaceutical Care. The Panjen Pharmacy in Wedomartani Village, Sleman is still constrained in implementing pharmaceutical services. Based on the results of observations to partners, these problems resulted from A limited number of human resources, lack of facilities and infrastructure, the absence of standardized etiquette, no drug information handbook, and there is no counseling card. The average number of visits by patients who buy drugs at the Panjen Pharmacy per day reaches 35-70 people. So it is necessary to improve services to provide a sense of security to patients about the use of drugs to be consumed. The outcome of this service activity is to optimize Panjen Pharmacy services through increasing human resource capacity, improving infrastructure, availability of standard etiquette, counseling cards, and drug information book achieved with the Participatory Rural Appraisal (PRA) participatory community empowerment model. The continuity of this service activity is the achievement of consistency in the application of a good and correct rationing system, both in terms of Human Resources Utilization (Human Resources), as well as in terms of a management information system that can guarantee the availability of the right type of drug, the right amount, the right quality and the right time. , thus making the pharmacy better in terms of service to the community and
\end{abstract}


JAMALI - Volume. 02, Issue. 02, September 2020

healthier.

Keywords: Panjen pharmacy, patient, service

\section{PENDAHULUAN}

Paradigma Pelayanan kefarmasian pada saat ini telah bergeser orientasinya dari obat (Drug Oriented) ke pasien yang mengacu kepada Pharmaceutical Care. Kegiatan pelayanan kefarmasian yang semula hanya berfokus pada pengelolaan obat sebagai komoditi menjadi pelayanan yang komprehensif yang bertujuan untuk meningkatkan kualitas hidup dari pasien. Konsekuensi atas perubahan orientasi tersebut, apoteker dituntut untuk meningkatkan pengetahuan, ketrampilan komunikasi dan perilaku agar dapat melaksanakan interaksi langsung dengan pasien dan tenaga kesehatan lainnya.Apoteker dituntut untuk menjalankan standar kefarmasian di apotek untuk menghindari kemungkinan terjadinya kesalahan pengobatan (medication error) dalam proses pelayanan.

Salah satu interaksi antara apoteker dengan pasien melalui konseling obat, konseling obat sebagai salah satu metode edukasi pengobatan secara tatap muka atau wawancara merupakan usaha untuk meningkatkan pengetahuan dan pemahaman pasien dalam penggunaan obat (Depkes RI, 2006). Menurut KEPMENKES RI Nomor 1027/MENKES/SK/IX/2004 tentang Standar Pelayanan Kefarmasian di Apotek, konseling adalah suatu proses komunikasi dua arah yang sistematik antara apoteker dan pasien untuk mengidentifikasi dan memecahkan masalah yang berkaitan dengan obat dan pengobatan (Depkes RI, 2004). Di dalam prakteknya, konseling obat melakukan penyampaian dan penyediaan nasehat-nasehat yang berkaitan dengan obat, yang didalamnya terdapat implikasi diskusi timbal balik dan tukar menukar opini (Siregar dan Kumolosari, 2004).

Dengan adanya diskusi timbal-balik dan tukar menukar opini antara pasien dan apoteker diharapkan dapat diambil keputusan bersama tentang terapi yang akan dijalani (Rantucci, 2006). Peran terpenting konseling pasien adalah memperbaiki kualitas hidup pasien dan menyediakan pelayanan yang bermutu untuk pasien (Rantucci, 2006). Dengan adanya konseling obat diharapkan pasien mendapatkan pengetahuan dan pemahaman pasien dalam penggunaan obat sehingga berdampak pada kepatuhan pengobatan dan keberhasilan dalam proses penyembuhan penyakitnya (Depkes RI, 2006).

Pemberian konseling obat dapat mengurangi terjadinya efek samping obat pada pengobatan yang dijalani oleh pasien, dan dapat meningkatkan kepatuhan pasien. (Poudel dkk, 2008). Melalui konseling, apoteker dapat menyelidiki kebutuhan pasien saat ini dan akan datang. Apoteker dapat menemukan apa yang perlu diketahui oleh pasien, keterampilan apa yang perlu dikembangkan dalam diri pasien, dan masalah yang perlu diatasi. Selain itu, apoteker diharapkan dapat menentukan perilaku dan sikap pasien yang perlu dirubah (Rantucci, 2006). Untuk memberikan konseling obat yang benar terhadap pasien mengenai obat, Apoteker diwajibkan untuk memiliki beberapa sumber informasi. Sumber infomasi yang digunakan bisa berasal dari pustaka, media cetak, dan internet (Rantucci, 2006). Sumber informasi obat meliputi antara lain dokumen, fasilitas, 3 lembaga dan manusia. Sedangkan dalam praktiknya sumber informasi obat digolongkan menjadi tiga macam yaitu sumber informasi primer, sumber informasi sekunder dan sumber informasi tersier (Kurniawan dan Chabib, 2010). 
Selain itu, Persediaan obat merupakan salah satu investasi terbesar apotek yang nilainya terus meningkat, sehingga diperlukan manajemen persediaan obat yang optimal untuk meminimalkan biaya investasi. Faktor utama dalam mengoptimalkan manajemen persediaan obat adalah akurasi prediksi persediaan obat. (Gustriansyah, R., dkk, 2017). Apotek Panjen saat ini telah memiliki Sistem Informasi Manajemen Apotek, yang merupakan aplikasi sistem terpadu secara komputerisasi dalam pengelolaan data obat, hingga perhitungan keuangan sistematis, sehingga dapat meminimalisir kesalahan dalam perekaman stok obat, kadaluarsa obat, dan daftar harga terbaru obat.

Berdasarkan hasil pengabdian di Apotek Panjen dengan kegiatan intensif yang dilakukan dengan stakeholder apotek, saat ini telah tercapai sebuah sistem perapotekan yang lebih baik dari sebelumnya, ditinjau dari segi SDM (Sumber Daya Manusia) maupun antara apoteker dengan pasien yang datang berkunjung ke Apotek Panjen.

Keberlanjutan kegiatan pengabdian ini adalah tercapainya konsistensi penerapan sistem perapotekan yang baik dan benar, baik dari segi Pendayagunaan SDM (Sumber Daya Manusia), maupun dari segi sistem informasi manajemen perapotekan yang dapat menjamin ketersediaan obat yang tepat jenis, tepat jumlah, tepat mutu dan tepat waktu, sehingga menjadikan Apotek semakin baik dari segi pelayanan kepada masyarakat dan semakin sehat.

\section{METODE PENGABDIAN}

Berdasarkan Permasalahan-permasalahan yang ada, maka telah disepakati untuk menyelesaikan persolan tersebut melalui pelatihan, pendampingan, dan pengadaan sarana dan prasarana. Model pemberdayaan masyarakat untuk mengatasi persolan di atas menggunakan metode partisipatif Participatory Rural Apraisal (PRA). Pertimbangan dipilihnya metode ini adalah bahwa yang menghadapi masalah adalah mitra, oleh karena itu keterlibatan mitra dalam penentuan pemecahan masalah yang dihadapi dan penyelesaiannya sangat diperlukan. Berikut diagram alir metode kegiatan yang digunakan dalam mengatasi permasalahan mitra tersebut (Gambar 2.1)

\section{HASIL DAN PEMBAHASAN}

\section{Analisis Proses Pengabdian Masyarakat}

Pada kegiatan awal observasi, Apotek Panjen termasuk dalam kategori Apotek yang baru berkembang, karena baru berdiri pada tahun 2015. Ditinjau dari segi geografis, Apotek Panjen terletak di Dusun Panjen Desa Wedomartani Kecamatan Ngemplak Sleman Yogyakarta, yang lokasinya termasuk relatif jauh dari beberapa fasilitas kesehatan. Selain itu, ditinjau dari segi ekonomi, daya beli masyarakat di sekitar apotek sangat rendah, ditambah lagi dengan belum teredukasinya masyarakat akan pentingnya penggunaan obatobatan secara rasional.

Keadaan tersebut melatarbelakangi pentingnya kegiatan pengabdian ini, agar dapat menunjang terciptanya salah satu sistem pelayanan obat yang baik yang dilakukan oleh apotek sebagai salah satu usaha pelayanan penunjang kesehatan masyarakat. 
Beberapa upaya yang dilakukan agar Apotek Panjen dapat menjadi salah satu fasilitas kesehatan yang memadai adalah dengan cara peningkatan pelayanan, melalui peningkatan kapasitas dan kapabilitas SDM (Sumber Daya Manusia) melalui Peningkatan perbaikan sistem tata kelola apotek, maupun sistem pelayanan pada pelanggan (pasien).

\section{Analisis Penyelesaian Masalah Pelayanan Apotek Panjen}

Apotek yang beralamat di Desa Wedomartani Sleman ini, memiliki beberapa permasalahan, diantaranya: 1). Keterbatasan jumlah sumber daya manusia, 2). minimnya sarana dan prasarana, 3). Tidak adanya etiket berstandar, 4). Tidak adanya drugs information handbook, dan 5). Tidak adanya kartu konseling. Oleh karena itu, pengabdian masyarakat ini, dapat menjembatani terciptanya kondisi perbaikan sistem perapotekan yang berkelanjutan.

\subsection{Upaya Penyelesaian Keterbatasan fasilitas sarana dan prasarana}

Apotek Panjen memiliki keterbatasan sarana dan prasana yang dapat menunjang sistem perapotekan yang baik.

Saat ini Apotek Panjen telah dilengkapi dengan Sistem perapotekan yang baik dan benar, ditinjau dari segi Pendayagunaan SDM (Sumber Daya Manusia), maupun dari segi sistem informasi manajemen perapotekan yang dapat menjamin ketersediaan obat yang tepat jenis, tepat jumlah, tepat mutu dan tepat waktu, sehingga menjadikan Apotek semakin baik dari segi pelayanan kepada masyarakat dan semakin sehat. Sistem Manajemen Informasi Apotek, dapat mempermudah kinerja Apoteker dalam pengelolaan obat keluar-masuk obat, hingga masa kadaluarsa obat. Sehingga Apoteker dapat lebih fokus dalam prioritas jasa konseling pada pasien, tanpa harus direpotkan oleh pekerjaan administrasi. (Gambar 3.1)

\subsection{Upaya Penyelesaian Pelayanan Obat}

Tidak adanya pendampingan konseling kepada mitra untuk mengatasi permasalahan dan mengetahui riwayat penyakit pasien di karenakan tidak adanya ruang khusus konseling. Pelayanan obat hanya berdasarkan dari permintaan pasien, sehingga kedepan dapat menjadi permasalahan jika obat yang diberikan salah.

Kegiatan Pengabdian ini, menginisiasi adanya Kartu Konsultasi bagi pasien, sehingga seluruh kegiatan Konseling antara Pasien dengan Apoteker memiliki Rekam jejak yang tertelusur. (Gambar 3.2) Kegiatan pertama kali yang penting sebagai langkah awal perbaikan adalah berupa kemampuan SDM dalam melakukan komunikasi dengan Customer (Pelanggan/Pasien). Semakin baik sambutan diawal terhadap pelanggan, maka akan semakin menimbulkan kesan yang baik terhadap pelanggan, sehingga kesan tersebut dapat menciptakan kenyamanan terhadap pelanggan, baik sebagai konsumen maupun sebagai pasien. Hal tersebut dapat mencipakan komunikasi aktif 2 (dua) arah antara pihak Apoteker dengan pasien/pelanggan, yang dapat menyebabkan semakin membuat pasien semakin terbuka akan keluhan dan penyakit yang dideritanya, sehingga akan semakin mendapatkan arahan dan konseling obat yang tepat.

\subsection{Upaya Penyelesaian Informasi tentang Obat yang tidak jelas}

Sebelum kegiatan Pengabdian ini dilaksanakan, Apotek panjen belum memiliki etiket pada kemasan obat yang diberikan. Kegiatan pengabdian ini,menginisiasi pembuatan etiket kemasan terstandar, yang dapat memudahkan pasien untuk selalu patuh dalam pemakaian obat. (Gambar 3.3) 


\subsection{Upaya Penyelesaian Permasalahan Buku Referensi}

Kegiatan Pengabdian di Apotek Panjen, juga berinisiasi untuk dapat melengkapiApotek dengan Buku Referensi tentang informasi obat (drugs information book.). Upaya ini dilakukan untuk dapat memberikan konseling obat yang tepat kepada setiap pasien yang dapat berkonsultasi. (Gambar 3.4)

\section{KESIMPULAN}

Kegiatan pengabdian pada masyarakat yang berupa Optimalisasi sistem pelayanan dan penerapan sistem informasi perapotekan, melalui pengembangan Sumber daya yang ada. Kegiatan pengabdian ini dapat terlaksana sesuai dengan tujuan dan rencana pengabdian, yang mendapat dukungan penuh seluruh stakeholder apotek. Hasil dari kegiatan ini, dapat terlihat dari meningkatnya pelayanan yang baik kepada seluruh pelanggan (Customer Excellent). Adanya dukungan Sistem Manajemen Informasi yang ada di Apotek Panjen, akan semakin memudahkan pengendalian catatan persediaan obat beserta seluruh transaksi yang terjadi didalamnya. Kegiatan pengabdian ini, direkomendasikan untuk dapat dilanjutkan pada tahap lanjutan, atau dapat diaplikasikan pada Apotek lain di wilayah Yogyakarta dan sekitarnya, khususnya Apotek Rintisan (Apotek Lokal).

\section{UCAPAN TERIMA KASIH}

Ucapan terima kasih terutama ditujukan kepada Direktorat Penelitian dan Pengabdian Masyarakat (DPPM) UII atas pendanaan penuh pada Hibah ini. Ucapan terima kasih juga disampaikan kepada pihak-pihak yang telah membantu pelaksanaan pengabdian masyarakat ini.

\section{DAFTAR PUSTAKA}

Anonim, 2007, Data Riset Kesehatan Dasar, Kementrian Kesehatan Indonesia.

Anonim, 2011, Drug Information Handbook, lexicomp, USA.

Cipolle, R., et al, 2008, Pharmaceutical Care Practice, Second Edition, McGraw Hill, New York.

Depkes RI, 2004, Sistem Kesehatan Nasional Tahun 2004, Jakarta

Depkes RI, 2006, Pedoman Penyelenggaraan dan Prosedur Rekam Medis. Rumah Sakit di Indonesia. Jakarta

Gustriansyah, R., D.I. Sensuse, and A. Ramadhan. 2016, "Decision Support System for Inventory Management in Pharmacy Using Fuzzy Analytic Hierarchy Process and Sequential Pattern Analysis Approach.” In CONMEDIA 2015 - International Conference on New Media 2015.

Kurniawan W.K., dan Chabib, L., 2010, Pelayanan Informasi Obat Teori dan. Praktik, Graha Ilmu, Yogyakarta.

Peraturan Pemerintah No. 51 tahun 2009 tentang Pekerjaan Kefarmasian, Halaman 118-127.

Siregar, C. J. P., dan Kumolosari E., 2004, Farmasi Klinik: Teori dan Penerapan, Penerbit Buku Kedokteran EGC, Jakarta.

Rantucci, M.J., 2006, Komunikasi Apoteker-Pasien : Panduan Konseling Pasien (Edisi Ke-2). Penerjemah: A.N. Sani, Penerbit Buku Kedokteran EGC, Jakarta 


\section{Gambar}

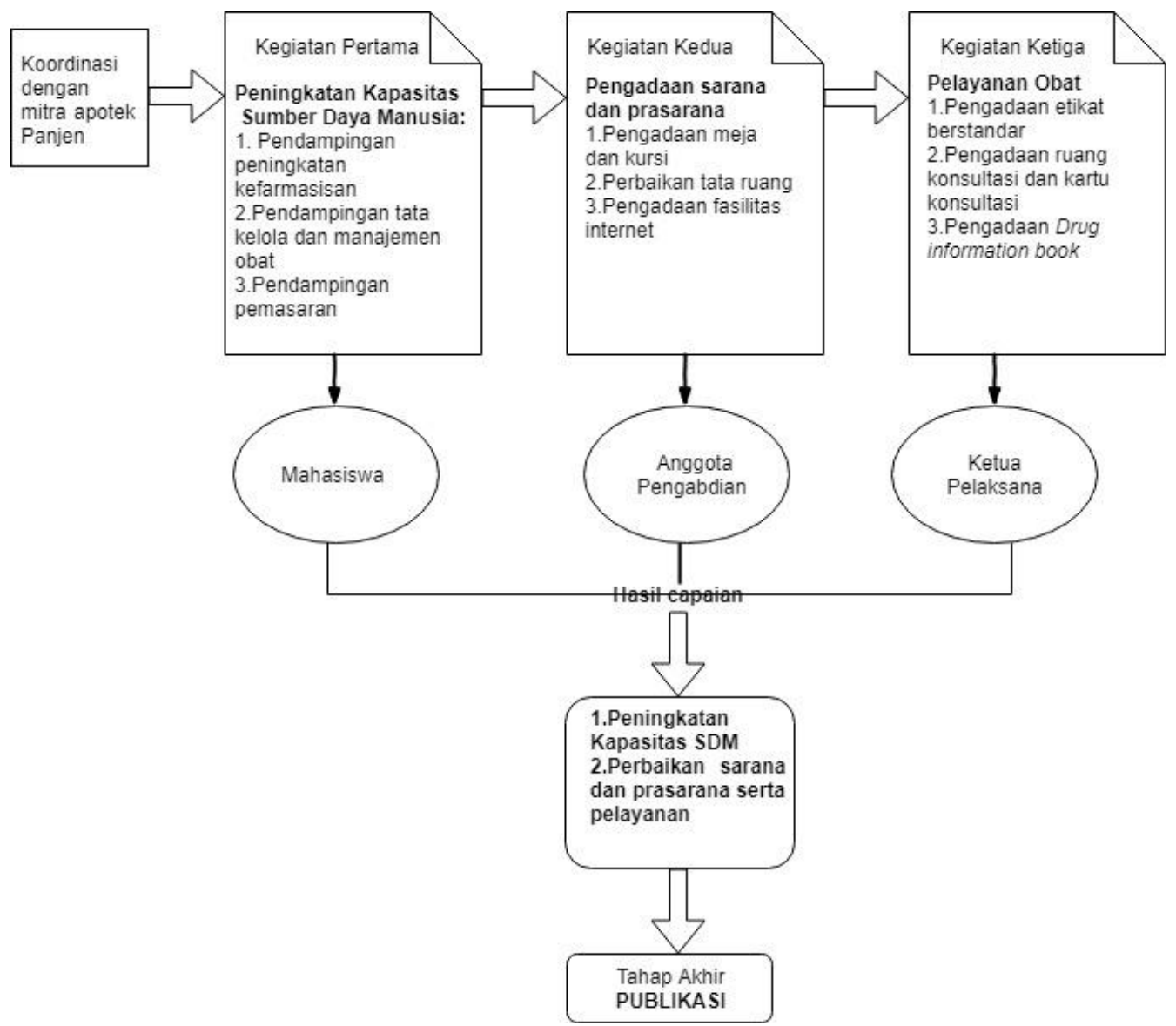

Gambar 2.1 Diagram alir metode kegiatan pelaksanaan kegiatan pengabdian
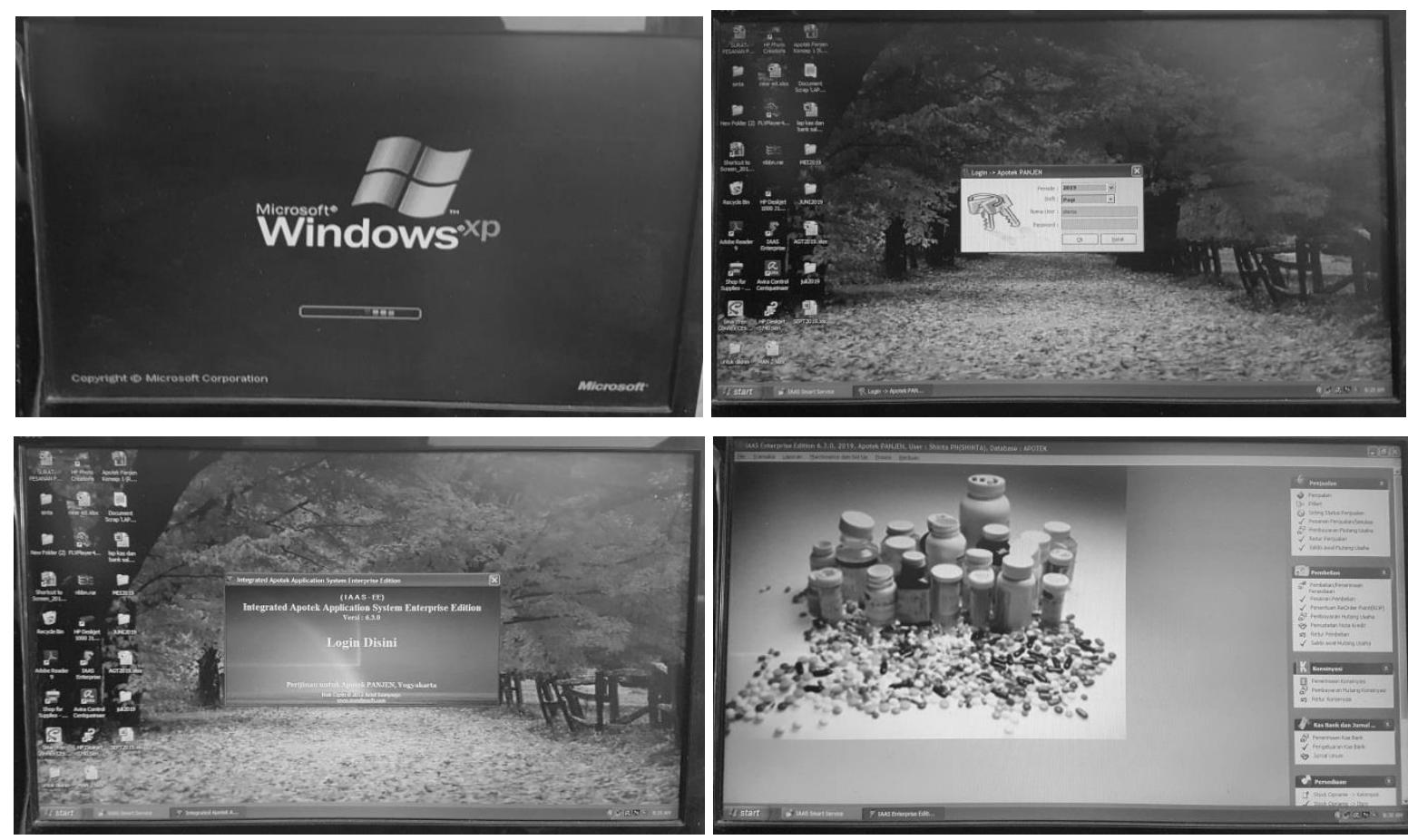
Gambar 3.1 Tampilan Layar Sistem Manajemen Informasi Apotek Panjen

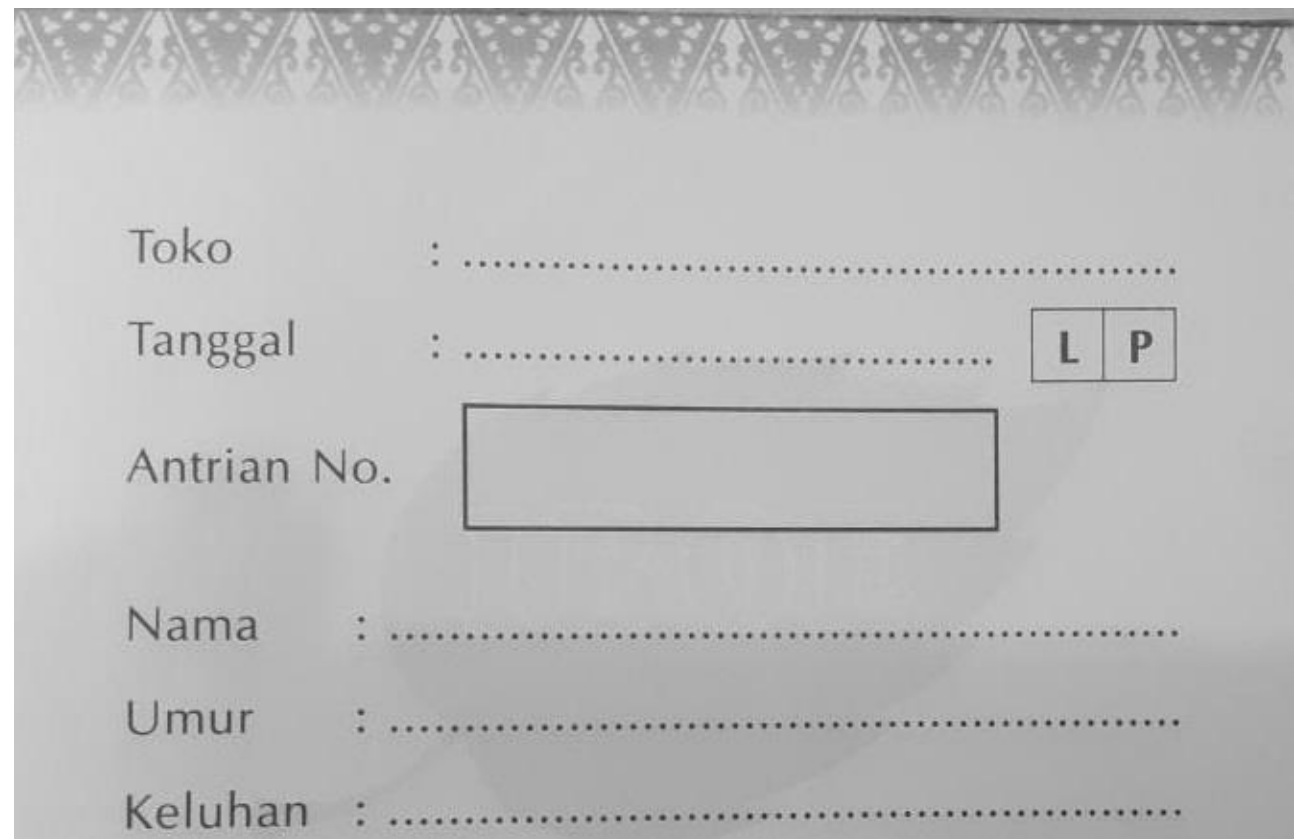

\begin{tabular}{|c|c|c|c|c|c|c|}
\hline & Tanggal & \multicolumn{5}{|l|}{ : } \\
\hline & \multicolumn{6}{|c|}{ Nama Pasien : } \\
\hline \multirow[t]{2}{*}{ Tes } & & \multicolumn{5}{|c|}{ Kategori } \\
\hline & & & Baik & Sedang & Buruk & Hipoglikemia \\
\hline \multirow[t]{2}{*}{ Gula Darah } & & Puasa & $80-100 \mathrm{mg} / \mathrm{dl}$ & $100-125 \mathrm{mg} / \mathrm{dl}$ & $\geq 126 \mathrm{mg} / \mathrm{dl}$ & $\leq 60 \mathrm{mg} / \mathrm{dl}$ \\
\hline & & Sewaktu & $80-144 \mathrm{mg} / \mathrm{dl}$ & $145-179 \mathrm{mg} / \mathrm{dl}$ & $\geq 180 \mathrm{mg} / \mathrm{dl}$ & \\
\hline \multirow[t]{2}{*}{ Asam Urat } & & Pria & Wanita & \multirow{6}{*}{\multicolumn{3}{|c|}{$\begin{array}{c}\text { KARTU PASIEN } \\
\text { Apotek Panjen } \\
085743874347\end{array}$}} \\
\hline & & $3,4-7,0$ & $2,4-6,0$ & & & \\
\hline \multirow[t]{2}{*}{ Kolesterol } & & Normal & Tinggi & & & \\
\hline & & $<200 \mathrm{mg} / \mathrm{dl}$ & $\geq 239 \mathrm{mg} / \mathrm{dl}$ & & & \\
\hline \multirow[t]{2}{*}{ Tensi } & & \multicolumn{2}{|c|}{ Normal } & & & \\
\hline & & \multicolumn{2}{|c|}{$120 / 80 \mathrm{~mm} / \mathrm{Hg}$} & & & \\
\hline
\end{tabular}

Gambar 3.2 Kartu Konseling dan Konsultasi Obat

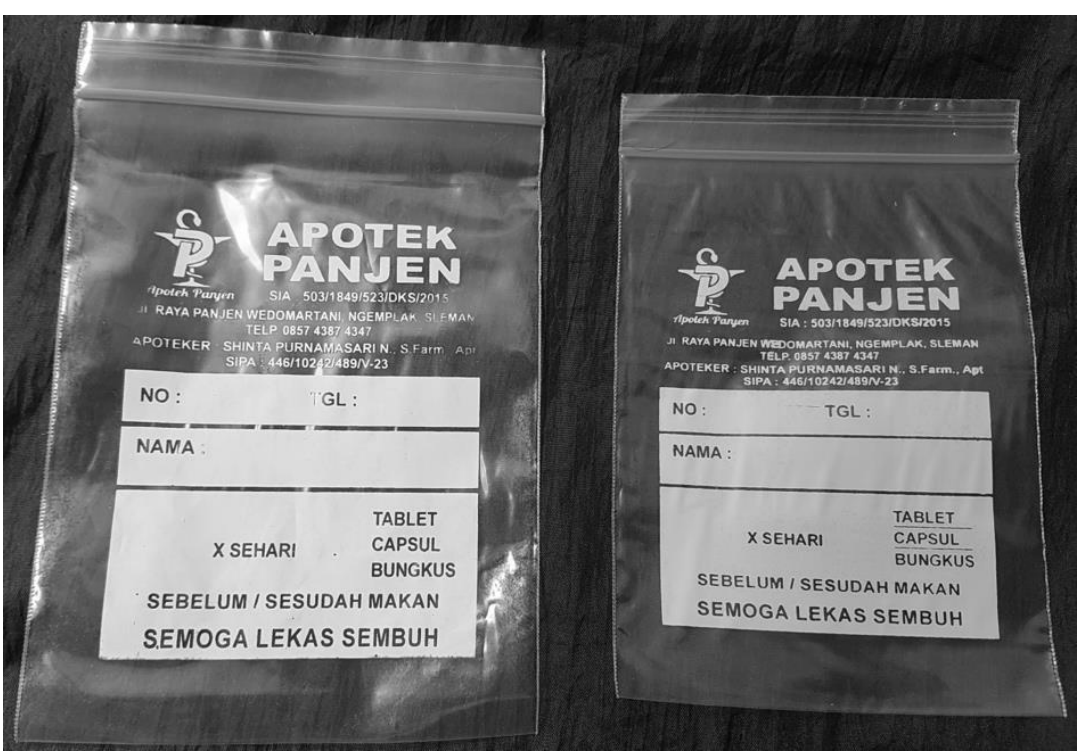

Gambar 3.3 Kemasan Obat dengan Etiket Penggunaan Obat 
JAMALI - Volume. 02, Issue. 02, September 2020

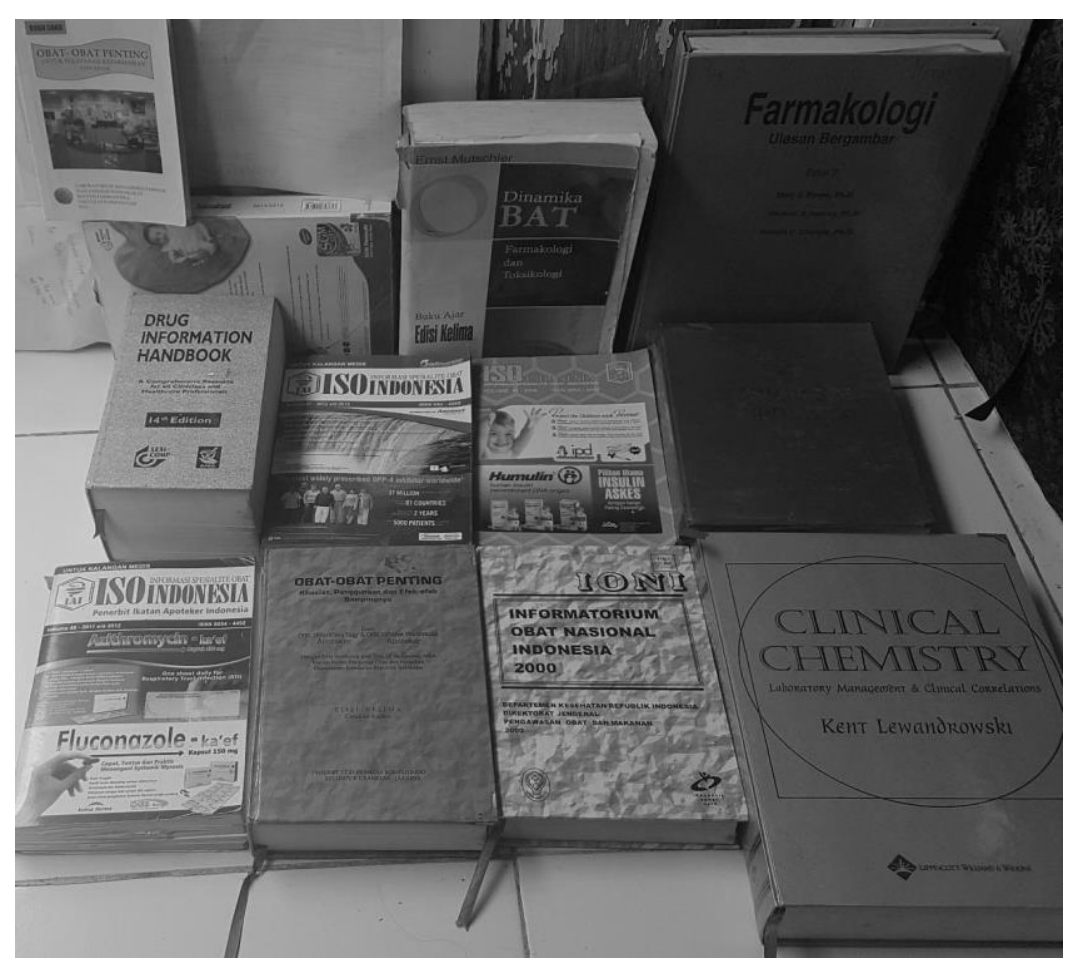

Gambar 3.4 Referensi informasi obat 